The grants will not be allocated to the individual universities until approximately November 18; ViceChancellors generally consider therefore that it is too early to decide whether or not they are adequate. Dr C. L. Bosanquet of Newcastle University considers that the proposals are at first sight reasonably encouraging and Dr D. G. Christopherson of Durham University welcomes the $£ 1.65$ million allocated to the purchase of university furniture and equipment for the current financial year. Each university is aware of its own needs but is ignorant of the needs of others and it may be some time therefore before an overall picture of the national situation is built up.

\section{Money for Schools}

Grants to students cost local authorities just over $£ 58$ million in 1965-66. The vast majority of the expenditure was made up by the full value awards, which cover fees and a maintenance element subject to parental income. There were 167,547 of these awards in $1965-66$, and they cost $£ 56$ million. The other $£ 2$ million is made up by a further 21,000 lesser value awards, made by local authorities either for nonscheduled courses, or to students who do not qualify academically for a full award.

The figures are given in the latest bulletin of statistics from the Department of Education and Science, Statistics of Education, Volume 5 (HMSO, $8 s$ 6d). The volume covers finance and awards, and shows that at the end of 1966 a total of $£ 124$ million had been approved for building schools and colleges of education.

\section{Science for Primary Schools}

THIs week the Nuffield Foundation brought out four books and three pamphlets in the Nuffield Junior Science Project, intended for teachers in primary schools. All are published by William Collins Sons and Co. Ltd. and they mark an important new development in Nuffield Science teaching.

The Nuffield approach of learning by doing is particularly suitable for primary schools, which have shown themselves more willing than most to abandon the traditional approaches to teaching. The books and booklets just published are intended to give the primary school teacher both a general idea of what Nuffield teaching means and practical examples which have been proved in the classrooms. One of the books is devoted to apparatus, and contains some remarkable examples made by children of average ability at an urban primary school. They include quite elaborate electrical circuits, including a buzzer working on a simple "make and break" circuit which went through no less than four development stages before reaching a final model. Development of the buzzers brought both miniaturization and increasing efficiency, and the final model incorporated three electromagnets and a threaded adjustor to control the amount of vibration.

The other books in the series describe the work which can be done with animal and plants in the classroom, and two guides for teachers with examples of projects which were done by classes in the early stage of the project. One of the three booklets describes how the changing seasons can be used to stimulate children's interest in science, and the other two describe experiments with mammals in the classroom, and, perhaps oddly, how science and history can be taught simultaneously. The introduction puts history firmly in its place-"Many people have been taught to regard history as consisting almost exclusively of politics . . . if history is to make sense to children, they must surely be encouraged to put themselves in the position of the men who made the discoveries which contributed to our present understanding of the world."

Whether the Nuffield Junior Science Project will redress this supposed imbalance remains to be seen. Its own fault is its tendency to elevate curiosity to the status of discovery.

\section{Causes of Death}

TEN years ago the World Health Organization produced a study of cardiovascular diseases and resulting mortality in twenty-four countries. Following the observation of low death rates from these diseases in Latin America, a further study was begun with the intention of providing a comprehensive account of the causes of mortality of adults in widely separated populations. The final results of the survey have just. been published by the Pan American Health Organization.

Eleven cities with annual death rates of about 2,000 and efficient death registration systems were selected for study. A twelfth, Ribeirão Prêto, with only 500600 deaths per year, was included because of the high incidence of Chagas infection. The cities, each an established medical centre, were Bogotá and Cali (Colombia), Carácas (Venezuela), Guatemala City (Guatemala), La Plata (Argentina), Lima (Peru), Mexico City (Mexico), Ribeirão Prêto and São Paulo (Brazil) and Santiago (Chile). Bristol and San Francisco were included for comparison. The aim was to investigate 2,000 deaths in each city for each of two consecutive years, by means of a standard questionnaire.

In Latin American countries birth rates and child mortality rates are high, and death rates must be adjusted to take this into account. Up to the mid-forty age group mortality rates in Latin American cities are double those of Bristol, while in the rural areas of South America they are probably about three times the Bristol level. Thus in Guatemala the mortality rate of young adults is six times that in Britain (Bristol figures being close to the national average). Cities in South America are more favourable than the country, but the reverse is true in San Francisco. For the 35-54 age group, death rates for the city are above the national average.

Two diseases emerge as leading causes of death. Diseases of the heart were the leading cause for males in eight cities, and for females in three. Cancer led in three cities for men and in nine cities for women. Cirrhosis of the liver, chiefly caused by alcohol, caused most male deaths in Santiago. Chagas disease was responsible for a large number of deaths in Ribeirão Prêto but did not appear significantly in any other city. La Plata had the highest number of deaths from cancer for both sexes; Bristol, not far behind, had the same number of male lung cancer victims. The figure for male cancer deaths in Mexico City was about half that for the other cities, but the reason is not known. This city had the highest death rate from diabetes mellitus. In the respiratory diseases, death from bronchitis was 